\title{
Population-based secular trends in lower- extremity amputation for diabetes and peripheral artery disease
}

\author{
Mohamad A. Hussain MD PhD, Mohammed Al-Omran MD MSc, Konrad Salata MD, Atul Sivaswamy MSc, \\ Thomas L. Forbes MD, Naveed Sattar MD PhD, Badr Aljabri MD, Ahmed Kayssi MD MPH, Subodh Verma MD PhD, \\ Charles de Mestral MDCM PhD
}

Cite as: CMAJ 2019 September 3;191:E955-61. doi: 10.1503/cmaj.190134

See related article at www.cmaj.ca/lookup/doi/10.1503/cmaj.191064

\begin{abstract}
BACKGROUND: The evolving clinical burden of limb loss secondary to diabetes and peripheral artery disease remains poorly characterized. We sought to examine secular trends in the rate of lowerextremity amputations related to diabetes, peripheral artery disease or both.
\end{abstract}

METHODS: We included all individuals aged 40 years and older who underwent lower-extremity amputations related to diabetes or peripheral artery disease in Ontario, Canada (2005-2016). We identified patients and amputations through deterministic linkage of administrative health databases. Quarterly rates (per 100000 individuals aged $\geq 40 \mathrm{yr}$ ) of any (major or minor) amputation and of major amputations alone were calculated. We used time-series analyses with exponential smoothing models to characterize secular trends and forecast 2 years forward in time.

RESULTS: A total of 20062 patients underwent any lower-extremity amputation, of which 12786 (63.7\%) underwent a major (above ankle) amputation. Diabetes was present in $81.8 \%$, peripheral artery disease in $93.8 \%$, and both diabetes and peripheral artery disease in $75.6 \%$. The rate of any amputation initially declined from 9.88 to 8.62 per 100000 between Q2 of 2005 and Q4 of
2010, but increased again by Q1 of 2016 to 10.0 per 100000 ( $p=0.003)$. We observed a significant increase in the rate of any amputation among patients with diabetes, peripheral artery disease, and both diabetes and peripheral artery disease. Major amputations did not significantly change among patients with diabetes, peripheral artery disease or both.

INTERPRETATION: Lower-extremity amputations related to diabetes, peripheral artery disease or both have increased over the last decade. These data support renewed efforts to prevent and decrease the burden of limb loss. ndividuals with diabetes or peripheral artery disease share a common fear: leg amputation. Frequently synergistic, peripheral neuropathy and arterial insufficiency predispose patients to foot ulceration, tissue death and infection., ${ }^{1,2}$ Diabetic foot ulcers are estimated to occur at a rate of $2 \%-4 \%$ per annum among individuals with diabetes in developed countries, ${ }^{3}$ and the numbers are continuing to rise. ${ }^{4}$ About one-third of diabetic foot ulcers fail to heal ${ }^{5}$ and many patients with nonhealing ulcers progress to lower-extremity amputation, with 1 diabetes-related lowerextremity amputation occurring every 30 seconds worldwide. ${ }^{3}$ When blood flow is sufficiently restricted to produce constant foot pain or gangrene, patients with peripheral artery disease have a 1 -year mortality rate of $22 \%$ and a 1 -year major amputation rate of
$22 \% .^{6}$ Together, peripheral artery disease and diabetes account for more than $80 \%$ of lower-extremity amputations in Canada. ${ }^{7,8}$

Emerging data show that several diabetes-related complications, such as acute myocardial infarction, stroke, end-stage renal disease and hyperglycemia crisis, have declined over the last 20 years, ${ }^{9}$ likely owing to improvements in pharmacotherapy and processes of care. Furthermore, hospital admissions for cardiovascular disease have declined by 54\% between 1994 and 2014 in Ontario, Canada. ${ }^{10}$ However, foot complications of diabetes and peripheral artery disease respond poorly to pharmacotherapy, and amputation-prevention efforts remain disjointed. ${ }^{11}$ It is unclear whether declines have occurred in rates of lowerextremity amputations related to diabetes and peripheral artery 
disease. Understanding temporal trends in disease burden is important to justify additional efforts to improve the delivery of foot care and amputation prevention. Therefore, we sought to examine secular trends in lower-extremity amputations among patients with diabetes, peripheral artery disease or both relative to the overall population.

\section{Methods}

\section{Study design and setting}

We designed a descriptive population-based repeated crosssectional study to examine temporal trends in the rates of lowerextremity amputations in Ontario, Canada (population 13.4 million [2016]). All amputation procedures in Ontario are funded under a single-payer public health system.

\section{Data sources}

The databases used in this study are stored at ICES, which is a prescribed entity under the Personal Health Information Protection Act that houses and allows for usage of patient health information for research purposes without patient consent. We used administrative health data sets to conduct this study - all of these databases are linked using a unique patient identifier, and they capture all health care interactions of Ontario residents in a single-payer health system. These data sets have been shown to be of high quality, ${ }^{12,13}$ and they are routinely used for population-based epidemiologic research. See Supplemental Table 1, Appendix 1, available at www.cmaj.ca/lookup/suppl/doi:10.1503/cmaj.190134/-/ DC1, for a complete list of the databases used in this study and Supplemental Figure 1, Appendix 1, for a graphic overview of the main databases used.

\section{Study population}

The study population included all individuals aged 40 years and older with a history of diabetes (type 1 or type 2), peripheral artery disease or both who underwent lower-limb amputation between Apr. 1, 2005, and Mar. 31, 2016. We first identified patients who underwent any (major or minor) lower-limb amputation as an inpatient or outpatient using codes from the Canadian Classification of Health Interventions. ${ }^{12}$ Major amputation was defined as any amputation at the above-, below- or throughknee level. Minor amputation was defined as any amputation at the level of the ankle, foot or toe. We then established 2 key population-defining variables: diabetes and peripheral artery disease. Diabetes was defined using a validated coding algorithm from the Ontario Diabetes Database (positive predictive value $80 \%$, sensitivity $86 \%$, specificity $97 \%$ ). ${ }^{13}$ Patients were deemed to have diabetes if the diagnosis date for diabetes in the Ontario Diabetes Database preceded the date of amputation (look-back window to 1991), or if International Classification of Diseases, 10th Revision (ICD-10) diagnosis codes for diabetes were present on the index amputation encounter. Peripheral artery disease was defined using ICD-10 diagnosis codes during a 3-year look-back window from the index amputation event. Peripheral artery disease codes have not been validated in our databases; therefore, to minimize risk of information bias in this regard, we carefully selected only relevant peripheral artery disease codes (see Supplemental Table 2, Appendix 1, for peripheral artery disease codes and their descriptions). We excluded patients with missing sex or unique identifier number, those younger than 40 years, and those with amputations related to malignancy, trauma or injury, congenital deformities or other diagnoses not related to diabetes or peripheral artery disease. See Supplemental Tables 2-4, Appendix 1, for a complete list of all codes used to capture the population in this study, and their accuracy.

\section{Covariates}

We established baseline demographic variables, including patient age, sex, rural or long-term care residence, immigration status and neighbourhood income quintile as a crude measure of socioeconomic status. ${ }^{14}$ Additional clinical variables were captured using a 3-year look-back window from the index amputation event using validated codes (Supplemental Methods and Supplemental Table 3, Appendix 1).

\section{Primary and secondary analyses}

In the primary analysis, we examined the quarterly rates (per 100000 individuals aged $\geq 40 \mathrm{yr}$ ) of any amputation among patients with diabetes, peripheral artery disease or both during the study period. In the secondary analyses, we examined rates of any amputation among patients with diagnosed diabetes (with or without peripheral artery disease), diagnosed peripheral artery disease (with or without diabetes), and those with both diabetes and peripheral artery disease. In addition, we examined rates of only major amputation in the aforementioned groups of patients. Finally, we examined rates of any amputation and major amputations by sex, and among populations we hypothesized to be at high risk for lower-limb amputation with potentially different temporal trends, including those on dialysis for end-stage renal disease, immigrants, those with the lowest income quintile and long-term care residents.

\section{Statistical analysis}

The study period was first divided into 44 quarterly intervals between Apr. 1, 2005, and Mar. 31, 2016. We then captured the total number of amputations performed within each quarter during the study period. If a patient had multiple amputations within one quarter, only the first amputation was included in the calculation of amputation rate for that particular quarter. However, if a patient had multiple amputations in different quarters, each amputation was used in the calculation of the amputation rate during the corresponding quarter. We used this approach because multiple amputations (e.g., toe followed by below-knee amputation) in the same quarter likely represent treatment for the same initial presentation, whereas amputations in different quarters (e.g., right toe in Q1 of 2009 and left below knee in Q4 of 2013) may represent progression of disease or disease in the contralateral limb. We calculated the rates of amputations per 100000 Ontario individuals aged 40 years and older using population data from the Registered Persons Database, which records demographic and vital statistics data for all individuals in Ontario. We opted to use the overall population as the denominator 
(rather than only individuals with a diagnosis of diabetes or peripheral artery disease) because this strategy allows for changes in the prevalence of diabetes and peripheral artery disease to influence amputation rates. Furthermore, many patients' first presentation with diabetes or peripheral artery disease may be with nonsalvageable ischemia, particularly in rural and remote communities with the highest rates of amputations; ${ }^{11}$ therefore, the use of overall population as the denominator allowed for more accurate rate calculation.

Temporal trends in rates of amputations were examined using time-series analysis, which is a statistical technique used for modelling autocorrelation in temporally sequenced data that is measured repeatedly in equal intervals of time. ${ }^{15}$ We fit exponential smoothing models (additive and multiplicative Winters models) to the rates of amputations overall and among the predefined subgroups - these models account for changes in level, trend and seasonality of temporally sequenced data ${ }^{16,17}$ (see Supplemental Methods, Appendix 1, for more information). Forecasts of amputation rates were carried out to Mar. 31, 2018, which was 2 years beyond the end of the study period.

All $p$ values are 2 -sided, and $p$ values less than 0.05 were considered statistically significant. All statistical analyses were conducted using SAS, version 9.4 (SAS Institute).

\section{Ethics approval}

The use of data in this project was authorized under section 45 of Ontario's Personal Health Information Protection Act, which does not require review by a research ethics board.

\section{Results}

\section{Baseline characteristics}

A total of 20062 unique patients with diabetes, peripheral artery disease or both underwent 27286 lower-limb amputations during the study period; $63.7 \%(12786 / 20062)$ of these patients underwent a major amputation.

The mean age was 68.7 (standard deviation 12.4) years, and $32.4 \%$ were women. A total of $81.8 \%$ had diabetes, $93.8 \%$ had peripheral artery disease and $75.6 \%$ had both. The overall comorbidity burden was high, as indicated by a Charlson Comorbidity Index score of 2 or greater in $77.8 \%$ of patients. Hypertension $(81.1 \%)$, congestive heart failure $(33.1 \%)$ and chronic obstructive pulmonary disease $(32.5 \%)$ were the most frequent individual comorbidities, and all of these comorbidities were more prevalent in the major-amputation group. The frequency of peripheral revascularization within 3 years before amputation was $17.5 \%$ in the any-amputation group and $23.2 \%$ in the major-amputation group. A total of $2.6 \%$ of patients in the any-amputation group had a previous minor amputation, and $16.3 \%$ in the major-amputation group had a previous minor amputation. See Table 1 for baseline characteristics of the study population.

\section{Major or minor amputations}

The overall rate of any (major or minor) amputation initially declined from 9.88 to 8.62 per 100000 individuals aged 40 years and older between Q2 of 2005 and Q4 of 2010, but the rate increased by Q1 of 2016 to 10.0 per 100000 , and our models predicted that amputation rates will continue to rise over the next 2 years $(p=0.003)$. Major or minor amputations related to peripheral artery disease followed a similar trend. A consistent increase, however, was observed in the rate of amputations

Table 1: Baseline characteristics of patients with a diagnosis of diabetes, peripheral artery disease or both who underwent lower-extremity amputations

\begin{tabular}{|c|c|c|}
\hline \multirow[b]{2}{*}{ Characteristic } & \multicolumn{2}{|c|}{ No. $(\%)$ of patients ${ }^{\star}$} \\
\hline & $\begin{array}{c}\text { Any } \\
\text { amputation } \\
n=20062\end{array}$ & $\begin{array}{c}\text { Major } \\
\text { amputation } \\
n=12786\end{array}$ \\
\hline Age, yr, mean \pm SD & $68.7 \pm 12.4$ & $69.8 \pm 12.3$ \\
\hline Sex, female & 6497 (32.4) & $4349(34.0)$ \\
\hline Rural residence $\dagger$ & $\begin{array}{c}n=20040 \\
3775(18.8)\end{array}$ & $\begin{array}{c}n=12769 \\
2215(17.3)\end{array}$ \\
\hline Neighbourhood income quintile $†$ & $n=19818$ & $n=12619$ \\
\hline 1 (lowest) & $5529(27.9)$ & $3621(28.7)$ \\
\hline 2 & $4264(21.5)$ & $2660(21.1)$ \\
\hline 3 & $3761(19.0)$ & $2419(19.2)$ \\
\hline 4 & $3414(17.2)$ & $2148(17.0)$ \\
\hline 5 (highest) & $2850(14.4)$ & $1771(14.0)$ \\
\hline Immigrant & $878(4.4)$ & $573(4.5)$ \\
\hline Long-term care residence & $1737(8.7)$ & $1572(12.3)$ \\
\hline \multicolumn{3}{|l|}{ Charlson Comorbidity Index score } \\
\hline 0 & $1357(6.8)$ & $478(3.7)$ \\
\hline 1 & $3096(15.4)$ & $2079(16.3)$ \\
\hline$\geq 2$ & $15609(77.8)$ & $10229(80.0)$ \\
\hline \multicolumn{3}{|l|}{ PAD and diabetes } \\
\hline PAD & $18822(93.8)$ & $12374(96.8)$ \\
\hline Diabetes & $16408(81.8)$ & $9967(78.0)$ \\
\hline PAD and diabetes & $15168(75.6)$ & $9555(74.7)$ \\
\hline Previous peripheral revascularization & $3502(17.5)$ & $2962(23.2)$ \\
\hline Previous minor limb amputation & $526(2.6)$ & $2085(16.3)$ \\
\hline Previous major limb amputation & $379(1.9)$ & $326(2.5)$ \\
\hline \multicolumn{3}{|l|}{ Comorbid conditions } \\
\hline Coronary artery disease & $3893(19.4)$ & $2882(22.5)$ \\
\hline Cerebrovascular disease & $990(4.9)$ & $713(5.6)$ \\
\hline Congestive heart failure & $6648(33.1)$ & 4797 (37.5) \\
\hline Hypertension & $16271(81.1)$ & $10718(83.8)$ \\
\hline COPD & $6521(32.5)$ & $4561(35.7)$ \\
\hline Chronic kidney disease & 3305 (16.5) & $2536(19.8)$ \\
\hline Dialysis & $2393(11.9)$ & $1867(14.6)$ \\
\hline
\end{tabular}

Note: $\mathrm{COPD}=$ chronic obstructive pulmonary disease, $\mathrm{PAD}=$ peripheral artery disease, $\mathrm{SD}=$ standard deviation.

*Unless stated otherwise.

†Missing values: rural residence, $22(0.1 \%)$ for any amputation and $17(0.1 \%)$ for major amputation; neighbourhood income quintile, 244 (1.2\%) for any amputation and 167 $(1.3 \%)$ for major amputation. 
among patients with diabetes, with the rate increasing from 8.07 to 8.59 per $100000(p=0.01)$. A similar, consistent increase in amputations was observed among patients with both diabetes and peripheral artery disease. See Figure 1 for rates of any amputation overall, and stratified by diabetes, peripheral artery disease, and both diabetes and peripheral artery disease.

\section{Major amputations}

The rates of major amputations did not change significantly in the overall study population (from 5.53 to 5.16 per 100000 ), and in the peripheral artery disease population (from 5.41 to 4.92 per $100000)$. Further, the rates of major amputations in patients with diabetes (from 4.25 to 4.10 per 100000 ) and in patients with both diabetes and peripheral artery disease (from 4.13 to 3.86 per $100000)$ remained stable during the study period without any significant decline. See Figure 2 for rates of major amputations.

\section{Subgroup analyses}

We examined temporal trends in the rates of any amputation and major amputation among several predefined subgroups (Supplemental Figures 2 and 3, Appendix 1). The rate of any amputation increased significantly among men (6.89 to 7.03 per $100000 ; p<$ 0.001 ), but did not change significantly among women. Among the immigrant population with diabetes, peripheral artery dis- ease or both, there was a numerical but nonsignificant increase in any amputation (66.7\% increase from 0.27 to 0.45 per 100000 ). The amputation rates remained relatively stable among individuals in the lowest income quintile, and those residing in long-term care facilities. We observed a $37.2 \%$ increase in the rate of any amputation (from 1.16 to 1.46 per 100000 ) among patients with diabetes, peripheral artery disease or both who were receiving dialysis - this increase did not reach statistical significance in our models.

\section{Interpretation}

Overall rates of amputations have increased in this population over the last decade, driven by a rise in minor amputations. Major amputations have remained stable in patients with diabetes and peripheral artery disease. We also observed increasing or stable trends in lower-extremity amputations when we examined rates by sex, dialysis treatment, immigrant status, lowest income quintile and long-term care residence. These data support renewed efforts to prevent and decrease the burden of limb loss among patients with diabetes or peripheral artery disease.

In contrast to our study, other studies examining national and regional trends in diabetes-related lower-extremity amputations

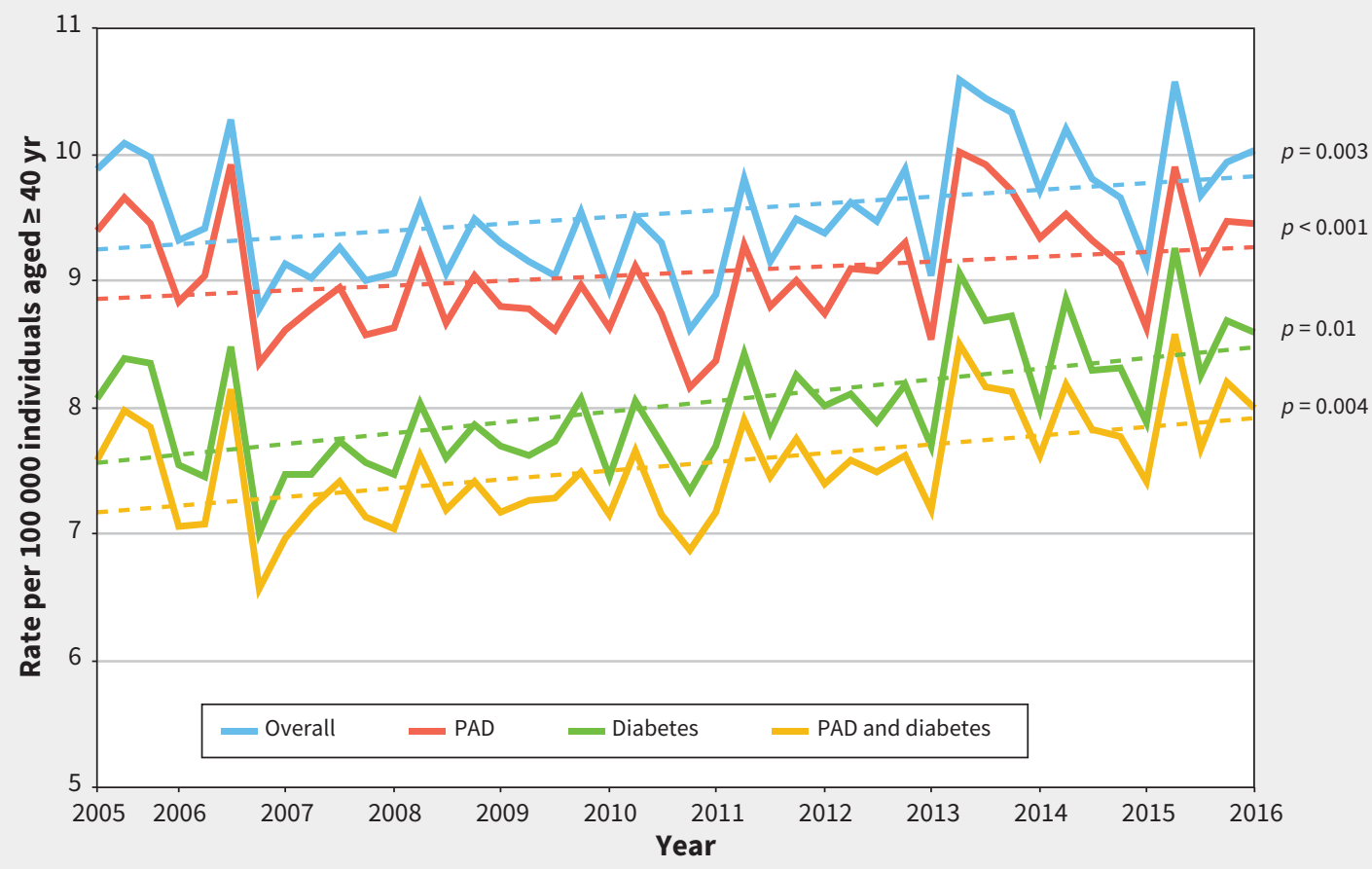

Figure 1: Major or minor lower-extremity amputations related to diabetes, PAD or both in Ontario, Canada. Note: PAD = peripheral artery disease. 
have consistently reported declining rates of amputations over the last decade. ${ }^{18-29}$ However, nearly all of these studies reported amputation rates per total individuals with a diagnosis of diabetes - this gives the incidence rate of amputations strictly for individuals diagnosed with diabetes.

In our study, we used the overall population as the denominator, which allows for changes in the prevalence of diabetes to influence amputation rates. Therefore, we observed increasing rates of overall diabetes-related amputations and stable rates of diabetes-related major amputations in part because of the rising prevalence of diabetes. This relation was also shown in a study by Gregg and colleagues, who found a 51\% decline in amputations among US individuals with diabetes between 1990 and $2010 .^{9}$ However, when expressed as a rate for the overall population (similar to the current study), the authors found no change in amputations over the study period. In contrast, the rate of acute myocardial infarction as a complication of diabetes declined regardless of whether it was presented as incidence among patients with diabetes ( $68 \%$ decline) or among the overall population (32\% decline). This suggests that unlike other cardiovascular complications of diabetes, which have been declining despite a rising prevalence of diabetes, lower-extremity amputations in individuals with diabetes have not declined at a population level.
A rising prevalence of diabetes and peripheral artery disease, and an aging population are some factors that may help explain this observation. Increased use of sodium-glucose co-transporter 2 (SGLT-2) inhibitors, a newer class of oral antihyperglycemic agent associated with an elevated risk of amputation, may also contribute to higher amputation rates in patients with diabetes. ${ }^{30}$ However, this is unlikely to have a significant effect in the current study, as 6 patients or fewer aged 66 years or older had filled a prescription for an SGLT-2 inhibitor within 150 days before the index amputation in this study population.

Few studies have examined temporal trends of amputations exclusively related to peripheral artery disease. ${ }^{31-36}$ Data from these studies suggest a decline in major amputations related to peripheral artery disease, and an increase in minor amputations related to peripheral artery disease over the last decade. This could be explained by advancements in cardiovascular risk-reduction therapies, ${ }^{37}$ greater uptake of endovascular interventions, ${ }^{36}$ and an increased focus on limb-preservation strategies that may result in a minor amputation to prevent a major one. In addition, individuals with diabetes tend to have more infrapopliteal or microvascular disease, which is less amenable to revascularization strategies than aortoiliac or femoropopliteal disease, which is more common in patients with peripheral artery disease without diabetes. Therefore, part of the decline in major amputations related to peripheral

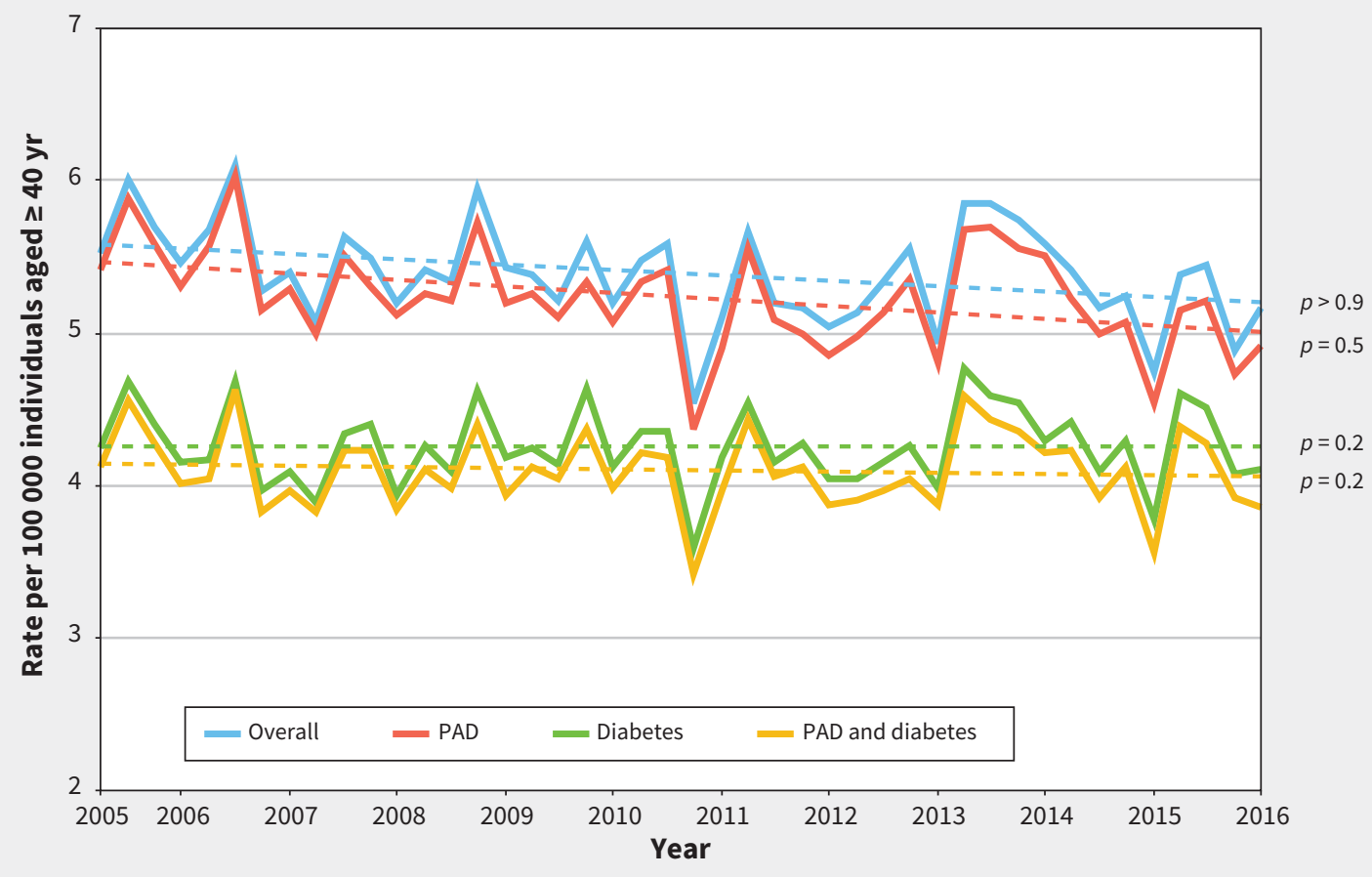

Figure 2: Major lower-extremity amputations related to diabetes, $\mathrm{PAD}$ or both in Ontario, Canada. Note: PAD = peripheral artery disease. 
artery disease may be explained by use of more effective surgical and endovascular revascularization strategies for more proximal arterial occlusive disease.

In contrast, individuals with diabetes require a greater focus on regular foot examinations, foot hygiene, foot care selfmanagement education, professionally fitted therapeutic footwear, and early recognition and treatment of foot ulcers. Unfortunately, almost $80 \%$ of high-risk patients with diabetes do not receive foot care education, and as many as $60 \%$ have never checked their feet or had their feet examined. ${ }^{38,39}$ This is probably because amputation-prevention programs have not been a focus of contemporary diabetes-management strategies. ${ }^{40}$

\section{Limitations}

The results of this study must be interpreted in light of some limitations. First, as with all population-based studies conducted using administrative databases, inaccurate coding could bias our results. However, we used validated coding algorithms where possible to mitigate this risk. ${ }^{12,13}$ Second, we were not able to stratify our results by diabetes type, nor were we able to capture the severity of diabetes or peripheral artery disease in our population. Furthermore, we could not capture other risk factors for diabetic foot disease and amputations, such as peripheral neuropathy and foot infection. Third, our findings were limited to the province of Ontario, which has a single-payer universal health care system. These results therefore may not be generalizable to other settings with different health systems. Finally, since we considered diabetes and peripheral artery disease jointly in this study, we were not able to determine whether the changes in amputation rates were due to factors specific to diabetes or peripheral artery disease. However, it is important to note that there is considerable overlap between diabetes and peripheral artery disease ( $75 \%$ of patients with amputations had both diagnoses in this study - a finding that has been replicated in other studies as well ${ }^{41}$ ), and similar multidisciplinary care structures are necessary to prevent amputation related to both diabetes and peripheral artery disease.

\section{Conclusion}

Although some diabetes-related complications are declining, the rate of lower-extremity amputations related to diabetes, peripheral artery disease or both is increasing. This finding shows a need for further research on establishing novel, structured multidisciplinary programs that focus on identifying and treating individuals with diabetes, peripheral artery disease or both, who are at high risk for developing foot complications, to decrease the clinical, psychological, social and economical burden of lowerlimb amputations.

\section{References}

1. Armstrong DG, Boulton AJM, Bus SA. Diabetic foot ulcers and their recurrence. N Engl J Med 2017;376:2367-75.

2. Singh N, Armstrong DG, Lipsky BA. Preventing foot ulcers in patients with diabetes. JAMA 2005;293:217-28.

3. Boulton AJ, Vileikyte L, Ragnarson-Tennvall G, et al. The global burden of diabetic foot disease. Lancet 2005;366:1719-24.

4. Hicks CW, Selvarajah S, Mathioudakis N, et al. Burden of infected diabetic foot ulcers on hospital admissions and costs. Ann Vasc Surg 2016;33:149-58.
5. Jeffcoate WJ, Chipchase SY, Ince P, et al. Assessing the outcome of the management of diabetic foot ulcers using ulcer-related and person-related measures. Diabetes Care 2006;29:1784-7.

6. Gerhard-Herman MD, Gornik HL, Barrett C, et al. 2016 AHA/ACC guideline on the management of patients with lower extremity peripheral artery disease: a report of the American College of Cardiology/American Heart Association task force on clinical practice guidelines. Circulation 2017;135:e726-79.

7. Imam B, Miller WC, Finlayson HC, et al. Incidence of lower limb amputation in Canada. Can J Public Health 2017;108:e374-80.

8. Kayssi A, de Mestral C, Forbes TL, et al. Predictors of hospital readmissions after lower extremity amputations in Canada. J Vasc Surg 2016;63:688-95.

9. Gregg EW, Li Y, Wang J, et al. Changes in diabetes-related complications in the United States, 1990-2010. N Engl J Med 2014;370:1514-23.

10. Tu JV, Khan AM, Ng K, et al. Recent temporal changes in atherosclerotic cardiovascular diseases in Ontario: clinical and health systems impact. Can J Cardiol 2017;33:378-84.

11. Hussain MA, Al-Omran M, Salata K, et al. A call for integrated foot care and amputation prevention pathways for patients with diabetes and peripheral arterial disease across Canada. Can J Public Health 2019;110:253-5.

12. Juurlink D, Preyra C, Croxford R, et al. Canadian Institute for Health Information discharge abstract database: a validation study. Toronto: Institute for Clinical Evaluative Sciences; 2006.

13. Hux JE, Ivis F, Flintoft V, et al. Diabetes in Ontario: determination of prevalence and incidence using a validated administrative data algorithm. Diabetes Care 2002;25:512-6.

14. Glazier RH, Creatore MI, Agha MM, et al.; Inner City Toronto Time Trends Working Group. Socioeconomic misclassification in Ontario's Health Care Registry. Can J Public Health 2003;94:140-3.

15. Juurlink DN, Mamdani MM, Lee DS, et al. Rates of hyperkalemia after publication of the Randomized Aldactone Evaluation Study. N Engl J Med 2004;351: 543-51.

16. Gardner ES. Exponential smoothing: the state of the art. J Forecast 1985;4:1-28.

17. Gardner ES Jr. Exponential smoothing: the state of the art - part II. Int J Forecast 2006;22:637-66.

18. Claessen H, Avalosse H, Guillaume J, et al. Decreasing rates of major lowerextremity amputation in people with diabetes but not in those without: a nationwide study in Belgium. Diabetologia 2018;61:1966-77.

19. Claessen H, Narres M, Haastert B, et al. Lower-extremity amputations in people with and without diabetes in Germany, 2008-2012 - an analysis of more than 30 million inhabitants. Clin Epidemiol 2018;10:475-88.

20. Carinci F, Massi Benedetti M, Klazinga NS, et al. Lower extremity amputation rates in people with diabetes as an indicator of health systems performance. A critical appraisal of the data collection 2000-2011 by the Organization for Economic Cooperation and Development (OECD). Acta Diabetol 2016;53:825-32.

21. Ahmad N, Thomas GN, Gill P, et al. The prevalence of major lower limb amputation in the diabetic and non-diabetic population of England 2003-2013. Diab Vasc Dis Res 2016;13:348-53.

22. Rasmussen BSB, Yderstraede KB, Carstensen B, et al. Substantial reduction in the number of amputations among patients with diabetes: a cohort study over 16 years. Diabetologia 2016;59:121-9.

23. Baba M, Davis WA, Norman PE, et al. Temporal changes in the prevalence and associates of diabetes-related lower extremity amputations in patients with type 2 diabetes: the Fremantle Diabetes Study. Cardiovasc Diabetol 2015;14:152.

24. Lazzarini PA, O'Rourke SR, Russell AW, et al. Reduced incidence of foot-related hospitalisation and amputation amongst persons with diabetes in Queensland, Australia. PLoS One 2015;10:e0130609.

25. Veresiu IA, lancu SS, Bondor C. Trends in diabetes-related lower extremities amputations in Romania - a five year nationwide evaluation. Diabetes Res Clin Pract 2015;109:293-8.

26. Lopez-de-Andres A, Jiménez-García R, Aragón-Sánchez J, et al. National trends in incidence and outcomes in lower extremity amputations in people with and without diabetes in Spain, 2001-2012. Diabetes Res Clin Pract 2015;108:499-507.

27. Lai $\mathrm{Y}-\mathrm{J}, \mathrm{Hu} \mathrm{H}-\mathrm{Y}$, Lin $\mathrm{C}-\mathrm{H}$, et al. Incidence and risk factors of lower extremity amputations in people with type 2 diabetes in Taiwan, 2001-2010. J Diabetes 2015;7:260-7.

28. Jørgensen ME, Almdal TP, Faerch K. Reduced incidence of lower-extremity amputations in a Danish diabetes population from 2000 to 2011. Diabet Med 2014;31:443-7.

29. Li Y, Burrows NR, Gregg EW, et al. Declining rates of hospitalization for nontraumatic lower-extremity amputation in the diabetic population aged 40 years or older: U.S., 1988-2008. Diabetes Care 2012;35:273-7.

30. Neal B, Perkovic V, Mahaffey KW, et al.; CANVAS Program Collaborative Group. Canagliflozin and cardiovascular and renal events in type 2 diabetes. N Engl J Med 2017;377:644-57. 
31. Behrendt C-A, Sigvant B, Szeberin Z, et al. International variations in amputation practice: a VASCUNET report. Eur J Vasc Endovasc Surg 2018;56:391-9.

32. Wendt K, Kristiansen R, Krohg-Sørensen K, et al. Norwegian trends in numbers of lower extremity revascularisations and amputations including regional trends in endovascular treatments for peripheral arterial disease: a retrospective crosssectional registry study from 2001 to 2014. BMJ Open 2017;7:e016210.

33. Heyer K, Debus ES, Mayerhoff L, et al. Prevalence and regional distribution of lower limb amputations from 2006 to 2012 in Germany: a population based study. Eur J Vasc Endovasc Surg 2015;50:761-6.

34. Kolossváry E, Ferenci T, Kováts $\mathrm{T}$, et al. Trends in major lower limb amputation related to peripheral arterial disease in hungary: a nationwide study (20042012). Eur J Vasc Endovasc Surg 2015;50:78-85.

35. Jones WS, Patel MR, Dai D, et al. Temporal trends and geographic variation of lower-extremity amputation in patients with peripheral artery disease: results from U.S. Medicare 2000-2008. J Am Coll Cardiol 2012;60:2230-6.

36. Al-Omran M, Tu JV, Johnston KW, et al. Use of interventional procedures for peripheral arterial occlusive disease in Ontario between 1991 and 1998: a population-based study. J Vasc Surg 2003;38:289-95.

37. Hussain MA, Al-Omran M, Mamdani M, et al. Efficacy of a guideline-recommended risk-reduction program to improve cardiovascular and limb outcomes in patients with peripheral arterial disease. JAMA Surg 2016;151:742-50.

38. De Berardis G, Pellegrini F, Franciosi M, et al. QuED Study Group. Physician attitudes toward foot care education and foot examination and their correlation with patient practice. Diabetes Care 2004;27:286-7.

39. Al Sayah F, Soprovich A, Qiu W, et al. Diabetic foot disease, self-care and clinical monitoring in adults with type 2 diabetes: the Alberta's Caring for Diabetes (ABCD) cohort study. Can J Diabetes 2015;39(Suppl 3):S120-6.

40. van Houtum WH. Barriers to the delivery of diabetic foot care. Lancet $2005 ; 366$ : 1678-9.

41. Kurowski JR, Nedkoff L, Schoen DE, et al. Temporal trends in initial and recurrent lower extremity amputations in people with and without diabetes in Western Australia from 2000 to 2010. Diabetes Res Clin Pract 2015;108:280-7.
Competing interests: Naveed Sattar reports personal fees from Amgen, AstraZeneca, Eli Lilly, Janssen, Napp Pharmaceuticals, Novo Nordisk and Sanofi, and grants and personal fees from Boehringer Ingelheim outside the submitted work. No other competing interests were declared.

This article has been peer reviewed.

Affiliations: Divisions of Vascular Surgery (Hussain, Al-Omran, Salata, de Mestral) and Cardiac Surgery (Verma), St. Michael's Hospital; Li Ka Shing Knowledge Institute of St. Michael's Hospital (Al-Omran, Verma, de Mestral); Department of Surgery (Hussain, Salata, Forbes, Kayssi), University of Toronto; Diabetes Action Canada (Hussain, Al-Omran, Salata, Forbes, Kayssi), Toronto, Ont.; King Saud University-Li Ka Shing Collaborative Research Program (Aljabri, Verma) and Department of Surgery (Aljabri), King Saud University, Riyadh, Kingdom of Saudi Arabia; ICES (Sivaswamy, de Mestral); Division of Vascular Surgery (Forbes), Peter Munk Cardiac Centre, University Health Network, Toronto, Ont.; Institute of Cardiovascular and Medical
Sciences (Sattar), University of Glasgow, Glasgow, Scotland, United Kingdom; Division of Vascular Surgery (Kayssi), Sunnybrook Health Sciences Centre, Toronto, Ont.

Contributors: All of the authors made substantial contributions to the conception and design of the study, and interpretation of data. Atul Sivaswamy did the statistical analyses. Mohamad Hussain drafted the manuscript, which all of the authors revised. Mohammed Al-Omran and Charles de Mestral provided study supervision and funding. Mohamad Hussain, Mohammed Al-Omran and Charles de Mestral are the guarantors for this work. All of the authors gave final approval of the version to be published and agreed to be accountable for all aspects of the work.

Study presentation: Part of the results from this study were presented at the Society for Vascular Surgery 2018 Vascular Annual Meeting, Boston, Massachusetts (June 20-23, 2018), and part of the results were presented at the World Heart Federation's World Congress of Cardiology \& Cardiovascular Health, Dubai, United Arab Emirates, (Dec. 5-8, 2018).
Disclaimer: This study was supported by ICES, which is funded by an annual grant from the Ontario Ministry of Health and Long-Term Care (MOHLTC). The opinions, results and conclusions reported in this paper are those of the authors and are independent from the funding sources. No endorsement by ICES or the Ontario MOHLTC is intended or should be inferred. All data sets used in this study were linked using unique encoded identifiers and analyzed at ICES. Parts of this material are based on data and information compiled and provided by the Canadian Institute for Health Information (CIHI). However, the analyses, conclusions, opinions and statements expressed herein are those of the author, and not necessarily those of $\mathrm{CIHI}$. The funders of the study had no role in study design, data collection, data analysis, data interpretation or writing of the report. The first and last authors had full access to the data and vouch for the accuracy of the analysis.

Accepted: July 9, 2019

Correspondence to: Charles de Mestral, demestralch@smh.ca 